\title{
Receptivity to Pro-Tobacco Media and Cigarette Smoking among Vocational High School Students in China
}

\author{
Xinguang Chen ${ }^{1,2}$, Jie Gong ${ }^{2}$, Han Zao $\mathrm{Li}^{3}$, Dunjin Zhou ${ }^{2}$ \& Yaqiong Yan $^{2}$ \\ ${ }^{1}$ Pediatric Prevention Research Center, Wayne State University, Detroit, USA \\ ${ }^{2}$ Wuhan Center for Disease Prevention and Control, Wuhan, China \\ ${ }^{3}$ Department of Psychology, University of Northern British Columbia, Canada \\ Correspondence: Han Z. Li, Department of Psychology, University of Northern British Columbia, Prince George, \\ V2N 4Z9 Canada. Tel: 1-250-960-6502. E-mail: lih@unbc.ca
}

Received: September 22, 2013

Accepted: December 2, 2013 Online Published: December 24, 2013

doi:10.5539/ijps.v6n1p7

URL: http://dx.doi.org/10.5539/ijps.v6n1p7

\begin{abstract}
The purpose of this study was to assess the association of receptivity to pro-smoking media and cigarette smoking among adolescents in China and updating data on smoking prevalence and typology. Data were collected from a random sample $(n=553)$ of vocational high school students in Wuhan, China, with a response rate of 99\%. Media receptivity was assessed using the Adolescent Tobacco Media Receptivity Scale (ATMRS, score range of 1-4). Smoking typology including habitual smokers and chippers, and smoking prevalence in one day, two days, one week, one month, two months, six months and one year were assessed. Reported smoking was verified using exhaled carbon monoxide. It was found that the initiation rates of smoking were $71.3 \%$ for boys and $27.4 \%$ for girls with $45 \%$ of the boys and $6.3 \%$ of the girls smoking in the past 30 days. Of the smokers, 40.7\% were self-stoppers and 29.6\% were chippers. The mean ATMRS score was 2.45 (SD=0.83) with boys scoring higher than girls. ATMRS scores were significantly associated with initiation and after-initiation smoking assessed at various durations. Findings of this study imply that Chinese youth are highly receptive to pro-tobacco media. Social marketing against tobacco advertising should be adopted as an important strategy for tobacco control in China. In addition, the period of 30-day appears to be an optimal choice to assess cigarette smoking as conventionally used in past research.
\end{abstract}

Keywords: adolescent health, cigarette smoking among adolescents, cigarette smoking in China, tobacco control in China

\section{Introduction}

In view of the high smoking rates in many developing countries (World Health Organization, 2011), tobacco control, particularly protecting adolescents from using tobacco may present one of the biggest challenges ahead. Researchers have found that up to $50 \%$ of boys and approximately $10 \%$ of adolescent girls in China are now experimenting with cigarette smoking (Yang et al., 2004; Jiang et al., 2006). Furthermore, an increasing trend in smoking and a declining trend in the age of smoking onset are reported in several studies (Yang et al., 1999; Chen et al., 2001; Yang et al., 2004).

As it is in many countries and places in the world, the high prevalence of tobacco use among Chinese adolescents could be attributable to intensive tobacco marketing by the tobacco industry in China. Although a number of legal measures have been taken to ban tobacco advertising, including the 1991 Tobacco Products Monopoly Law (Article 19), the 1994 Advertisement Law (Article 18), the 1995 Tobacco Advertising Management Regulations (Article 8), and the 2005 ratification of the Framework Convention on Tobacco Control of the World Health Organization (The Ministry of Health of China, 2007), yet, recent studies point to the high levels of exposure to tobacco advertisement in all possible venues including traditional (e.g., radio, television, billboards, and printed media) and new venues (e.g., internet, movies and TV series, event sponsorship, free samples, sale point display) presented by the tobacco industry through direct and indirect methods (Li et al., 2009; Yang et al., 2010; Lau, Chen, \& Ren, 2012; Yang et al., 2012).

Within an intensive tobacco marketing environment, receptivity to marketing messages as a cognitive process comprises a vital influence toward tobacco use (Bandura, 1977; Carson, Rodriguez, \& Audrain-McGovern, 
2005). According to the persuasive communication theory, receptivity to a media message includes four interrelated components: perception of, attitudes to, and internalization of the message, and the ability to resist temptation of the portrayed product (McGuire, 1985; Feighery, Borzekowski, Schooler, \& Flora, 1998). Rapid and uneven-paced development during adolescence makes adolescents a highly susceptible target to tobacco advertisements (Chen, Cruz, Schuster, Unger, \& Johnson, 2002; Gilpin, Distefan, \& Pierce, 2004). Evidence from diverse sources indicates that cognitive receptivity to pro-tobacco media is associated with increased susceptibility to smoking ( Feighery, Borzekowski, Schooler \& Flora, 1998; Pierce et al., 1998), heightened odds of smoking initiation, increased smoking behavior progression, and increased likelihood of current smoking (Chen , Cruz, Schuster, Unger \& Johnson, 2002; Pierce, Garcia, Saltó, Schiaffino \& Fernández, 2002; Naing et al., 2004; Carson, Rodriguez, \& Audrain-McGovern, 2005; Chen et al., 2006). However, to our knowledge, no previous study has examined this issue among adolescents in China.

Vocational high school students, in particular, may represent an at-risk population for receptivity to tobacco advertising and tobacco smoking. Chinese vocational high school education, with a total enrollment of 7.26 million, is a three-year employment-oriented, technical skills training program enrolling students who do not advance to regular high schools after completing nine years of compulsory education (The Ministry of Education of China, 2011). Data from reported survey studies with vocational high school students as a part of the study samples indicate high levels of health risk behaviors, including tobacco use (Anderson, et al., 2006; Xing, Ji, \& Zhang, 2006). Understanding media receptivity and its impact on cigarette smoking would be of great significance for tobacco control. In addition to receptivity to pro-tobacco media messages, a number of other factors have also been linked to increased risk of adolescent tobacco use, including smoking behaviors of peers, parents and teachers (Yang et al., 2004; Chen et al., 2006; Wen et al., 2007; Tanski, Stoolmiller, Gerrard, \& Sargent, 2011).

A highly relevant issue concerning tobacco research is the measurement of current smoking status. Self-reported smoking in the past month is conventionally used by almost all studies in both developing and developed countries. Other measurements, such as smoking in the past 60 days as recommended by the World Health Organization are also used by researchers. However, no study seems to have examined the extent to which different measurement periods affect study results. In addition, data are lacking on smoking typology (e.g., regular smoker, chipper, self-stopper and quitter) for adolescent smokers in China. Such data are of great significance in tobacco research and control as reported in studies conducted in developed countries (Shiffman, Kassel, Paty, Gnys, \& Zettler-Segal, 1994; Morissette et al., 2008; Coggins, Murrelle, Carchman, \& Heidbreder, 2009).

The purposes of this study are three folds: (1) provide up-to-date data on rates and typology of cigarette smoking among vocational high school students in China; (2) investigate the relationship between media receptivity and cigarette smoking; and (3) evaluate various measurement durations in studying adolescent smoking behavior.

\section{Method}

\subsection{Participants and Data Collection}

Participants of this study consisted of a sample of vocational high school students in Wuhan, central China. As a provincial capital city, Wuhan has a population of approximately 9 million with a per capita GDP of $\$ 5000$ RMB (approximately 800 USD) in 2010, close to the national average (China National Bureau of Statistics 2011). Students in year 1 and year 2 were selected to participate in this study; students in year 3 were excluded because of their time commitment to graduation exams and employment seeking. Participants in 17 classes (nine year-one classes and eight year-two classes) were randomly selected from the 35 classes available. All the 556 students in the selected classes were invited to participate; 3 refused, reaching a response rate of $99 \%$.

Prior to data collection, permission was obtained from the school administration to access the classes. Parental permission and student consent were also sought and obtained. Research protocol was approved by the Institutional Review Board of Wuhan Center for Disease Prevention and Control (CDPC), China and the Human Investigation Committee of Wayne State University, the United States.

Trained data collectors from Wuhan CDPC went to the school to administer the survey. Data were collected using the Chinese Student Health Behavior Questionnaire (CSHBQ), a paper-and-pencil survey we previously used in China (Zheng, Sussman, Chen, Wang, Xia et al., 2004; Lau, Chen, \& Ren., 2012). The participants filled out the questionnaire in their classrooms. It took approximately 20-30 minutes for most students to complete the survey. After completing the survey, participants were asked to exhale breath in the $\mathrm{PiCO}^{+\mathrm{TM}}$ (Smokerlyzer, USA) individually to assess carbon monoxide (CO) in the exhaled air as a biomarker of smoking. 


\subsection{Measures and Covariates}

\subsubsection{Receptivity to Pro-Tobacco Media}

Receptivity to pro-tobacco media was assessed using the Adolescent Pro-Tobacco Media Receptivity Scale (ATMRS). ATMRS is a 4-item scale we developed with reference to McGuire (1985), which followed a persuasive communication conceptual framework of perception, liking, internalizing of commercial messages and ability to resist the temptation of such messages. This framework has been used to assess receptivity to pro-tobacco media among adolescents in the United States (Pierce et al., 1998; Unger \& Chen, 1999; Chen et al., 2002). The item used to assess adolescents' perception of tobacco advertisement was "I think many tobacco commercials are terrific." The item used to assess liking of tobacco advertisement was "I like watching all kinds of tobacco commercials." The item used to assess internalization of tobacco advertisement was "I understand the meanings of many tobacco commercials." And the item used to assess the perceived capability of refusal temptations from pro-tobacco advertisement was "I wouldn't say no to the free tobacco promotional gifts, such as a t-shirt." A 5-point Likert scale ( $1=$ "totally disagree" to $5=$ "totally agree") was used for item scoring, and Cronbach alpha was 0.70 for the ATMRS. Mean scores were calculated such that a higher score indicated greater media receptivity.

\subsubsection{Measurement of Smoking Behaviors}

To better assess smoking behavior, we focused on rate of smoking initiation, age of smoking onset, incidence, frequency and amount of cigarettes smoked in several consecutive durations from lifetime, to the past year, past 6 months, past 2 months, past month, past week, past two days, and the survey day. Lifetime smoking or smoking initiation was assessed using the question "Please think from your very early childhood till now; have you ever smoked a cigarette during this period, even a few puffs?" To assess the age of smoking initiation, students who responded positively to the question regarding lifetime smoking (described above) were further asked "If you smoked, how old were you when you smoked your first cigarette?"

Smoking status was assessed in seven time periods: today, past two days, past week, past month, past two months, past six months, and past year. Smoking status was assessed by this question: "Please think of [the period]. Have you smoked cigarettes during [the period]?" (1=Yes, almost every day; $2=$ Yes, at least weekly if not daily; $3=$ Yes, occasionally; and $4=\mathrm{No}$, not smoking in [the period]). For example, smoking in the past month was assessed with the question: "Please think of the past 30 days, including today. Have you smoked any cigarettes in the last month? " Data collected from these questions were used to assess the incidence of cigarette smoking for each of the six time periods, and data collected for the past month were used in assessing the frequency of smoking. After each of these questions, students were further asked "If you smoked during [the period], on average, how many cigarettes did you smoke per day?" Data collected for the past month were used in assessing the amount of cigarette smoking. In addition, the reported number of cigarettes smoked per day was categorized into four levels: 1 cigarette, 2-5, 6-9 and $\geq 10$ cigarettes per day for frequency counting, following the categorization commonly used in the literature (Chen et al., 2004; Jones, Kann, \& Pechacek, 2011).

Students, who reported having smoked, were further asked: "Do you have a smoking habit?" Students who responded "No, I tried a couple of times and then stopped" were coded as "Self-Stoppers"; students, responded "Yes, I once had a smoking habit, but I am not smoking now" were coded as "Quitters"; students who responded "No, sometimes I smoke and some other times I do not smoke" were coded as "Chippers"; and lastly students who responded "Yes, I do now have a smoking habit" were coded as "Habit smokers".

To assess the validity of self-reported smoking behavior, CO levels in the exhaled air were obtained. A significant correlation was found between the $\mathrm{CO}$ level and self-reported frequency of smoking and number of cigarettes smoked using correlation analysis, with Pearson Correlations varying from 0.38 to 0.50 , and $\mathrm{p}<0.01$ for all correlations. $\mathrm{CO}$ in the exhaled air reflects tobacco exposure in the past 6-9 hours, and has been used as an effective biomarker to verify self-reported smoking data (Jatlow, Toll, Leary, Krishnan-Sarin, \& O'Malley, 2008).

\subsubsection{Other Influential Factors as Covariates}

To better assess the association between media receptivity and cigarette smoking, variables with potentials to affect media receptivity and smoking behavior of adolescents were assessed, including smoking behaviors of father, mother, teachers, friends, and the general public. To assess parental smoking, this question was asked "Does your mother/father smoke?" with answer options "Yes" and "No". Smoking behavior among the other three groups of people was assessed by this question: "Among your [teachers/friends/the general public], how many of them do you think are smokers?" Each question was assessed using a 5-point scale with 1 = "Almost 
everyone", 2= "Most of them", $3=$ "About half of them", 4= "Less than a half", and 5= "Almost none". The item scores were reversely coded such that higher scores reflected a perception of more smokers.

\subsubsection{Demographic Variables as Covariates}

School performance was assessed by the question "How would you rate your ranking in the class during the last semester?" A five-level scale (top 10 percent, above average, around average, below average, and lowest 10 percent) was used. Family income (RMB per month) was assessed using a 4-level scale (<1000 Yuan, 1000-1999 Yuan, 2000-2999 Yuan, and $\geq 3000$ Yuan).

\subsection{Data Processing and Statistical Analysis}

Data were manually entered into a computer by trained researchers in Wuhan CDC. The $100 \%$ double-entry protocol was followed to reduce data entry errors. Frequency, rate, ratio, mean and Standard Deviant (SD) were calculated to describe the study sample and to assess the levels and patterns of cigarette smoking. Gender differences were assessed using Student t-tests for continuous variables and Chi-square tests for categorical variables. Cronbach alpha was used to assess reliability of the media receptivity scale ATMRS. Association between media receptivity and cigarette smoking were assessed using bivariate t-test (for continuous variables) and chi-square test (for categorical variables) first and then verified using logistic regression controlling for covariates and demographic variables. Considering the large gender differences in smoking prevalence, most analyses were either conducted by gender or gender was included as a control variable. Statistical analyses were done using the software SAS 9.2 (SAS Institute, Cary, NC).

\section{Results}

\subsection{Sample Characteristics}

Table 1 shows that among the 553 participants, 275 (49.7\%) were boys, and $278(50.3 \%)$ were girls, with an average age of 16.3 years $(\mathrm{SD}=0.98)$. Approximately $60 \%$ of the students reported family income less than 2000 RMB per month (approximately 300 USD). No significant gender differences were found in age and family income.

Table 1. Selected characteristics of the vocational high school student sample

\begin{tabular}{|c|c|c|c|}
\hline Characteristics & $\begin{array}{l}\text { Male } \\
\text { N (\%) }\end{array}$ & $\begin{array}{l}\text { Female } \\
\text { N (\%) }\end{array}$ & $\begin{array}{l}\text { Total } \\
\text { N (\%) } \\
\end{array}$ \\
\hline Total & $275(49.7)$ & $278(50.3)$ & $553(100.0)$ \\
\hline \multicolumn{4}{|l|}{ Age (in years) } \\
\hline$\leq 15$ & $65(23.6)$ & $78(28.1)$ & $143(25.9)$ \\
\hline 16 & $87(31.6)$ & $90(32.4)$ & $177(32.0)$ \\
\hline 17 & $85(30.9)$ & $81(29.1)$ & $166(30.0)$ \\
\hline$\geq 18$ years old & $38(13.8)$ & $29(10.4)$ & $67(12.1)$ \\
\hline Mean (SD) & $16.3(0.99)$ & $16.2(0.97)$ & $16.3(0.98)$ \\
\hline \multicolumn{4}{|l|}{ School grade } \\
\hline Year 1 & $146(53.1)$ & $154(55.4)$ & $300(54.2)$ \\
\hline Year 2 & $129(46.9)$ & $124(44.6)$ & $253(45.8)$ \\
\hline \multicolumn{4}{|l|}{ School performance } \\
\hline Top $10 \%$ & $13(4.8)$ & $4(1.4)$ & $17(3.1)$ \\
\hline Above average & $47(17.2)$ & $37(13.4)$ & $84(15.3)$ \\
\hline Average & $124(45.4)$ & $151(54.5)$ & $275(50.0)$ \\
\hline Below average & $55(20.2)$ & $65(23.5)$ & $120(21.8)$ \\
\hline Bottom $10 \%$ & $34(12.4)$ & $20(7.2)$ & $54(9.8)$ \\
\hline \multicolumn{4}{|c|}{$\begin{array}{l}\text { Family income (RMB } \\
\text { per month) }\end{array}$} \\
\hline$<1000 \mathrm{RMB}$ & $54(19.8)$ & $58(21.1)$ & $112(20.5)$ \\
\hline 1000 - RMB & $93(34.2)$ & $108(39.3)$ & $201(36.8)$ \\
\hline 2000 - RMB & $74(27.2)$ & $67(24.4)$ & $141(25.8)$ \\
\hline $3000+\mathrm{RMB}$ & $51(18.8)$ & $42(15.3)$ & $93(17.0)$ \\
\hline
\end{tabular}

Note: The exchange rate of RMB to US dollars in 2011 was 6.8 RMB: \$1.0. Some of the frequency counts were not added up to the total due to missing data. 


\subsection{Levels and Patterns of Cigarettes Smoking}

Table 2 shows that among the 553 participants, 272 (49.3\%) initiated smoking, 33.3\% smoked for the first time before 13 years of age, with an average age of $12.9(\mathrm{SD}=3.1)$ years. The incidence of past-week smoking was $21.7 \%$, increasing to $25.6 \%$ for past-month smoking, and $30.8 \%$ for past-year smoking.

Table 2. Patterns of cigarette smoking among vocational high school students in Wuhan, China, 2011

\begin{tabular}{|c|c|c|c|}
\hline Smoking Pattern & Male, $\mathbf{N}=\mathbf{2 7 5}$ & Female, $\mathbf{N}=\mathbf{2 7 8}$ & Total, $N=553$ \\
\hline \multicolumn{4}{|l|}{ Smoking initiation** } \\
\hline Rate of initiation, $\mathrm{n}(\%)$ & $196(71.3)$ & $76(27.4)$ & $272(49.3)$ \\
\hline \multicolumn{4}{|l|}{ Age of initiation } \\
\hline$\leq 8$ years old, $\mathrm{n}(\%)$ & $17(9.2)$ & $9(13.0)$ & $26(10.3)$ \\
\hline $9-10$ years old, $n(\%)$ & $22(12.0)$ & $6(8.7)$ & $28(11.1)$ \\
\hline 11 - 12 years old, n (\%) & $25(13.6)$ & $5(7.3)$ & $30(11.9)$ \\
\hline 13 - 14 years old, n (\%) & $57(31.0)$ & $22(31.9)$ & $79(31.2)$ \\
\hline $15-16$ years old, $n(\%)$ & $50(27.2)$ & $25(36.2)$ & $75(29.6)$ \\
\hline 17 years and older, $\mathrm{n}(\%)$ & $13(7.1)$ & $2(2.9)$ & $15(5.9)$ \\
\hline Mean (SD) & $13.0(3.0)$ & $12.9(3.3)$ & $12.9(3.1)$ \\
\hline Missing, $\mathrm{n}$ & 12 & 7 & 19 \\
\hline \multicolumn{4}{|l|}{ Incidence of smoking** } \\
\hline Smoked in the past week, $\mathrm{n}(\%)$ & $102(38.9)$ & $13(4.9)$ & $115(21.7)$ \\
\hline Smoked in the past month, $\mathrm{n}(\%)$ & $118(45.4)$ & $17(6.3)$ & $135(25.6)$ \\
\hline Smoked in the past year, $\mathrm{n}(\%)$ & $136(50.2)$ & $32(11.6)$ & $168(30.8)$ \\
\hline \multicolumn{4}{|l|}{ Frequency of smoking** } \\
\hline \multicolumn{4}{|l|}{ (past month) } \\
\hline Occasionally, n (\%) & $51(42.9)$ & $12(70.6)$ & $63(46.7)$ \\
\hline Weekly, n (\%) & $34(28.6)$ & $5(29.4)$ & $39(28.9)$ \\
\hline Daily, n (\%) & $34(28.6)$ & $0(0.0)$ & $33(24.4)$ \\
\hline \multicolumn{4}{|l|}{ Amount of smoking** } \\
\hline$\leq 1$ cigarette, $\mathrm{n}(\%)$ & $34(29.8)$ & $12(63.2)$ & $46(34.6)$ \\
\hline $2-5$ cigarettes, $n(\%)$ & $63(55.3)$ & $6(31.6)$ & $69(51.9)$ \\
\hline $6-9$ cigarettes, $n(\%)$ & $10(8.8)$ & $1(5.3)$ & $11(8.3)$ \\
\hline$\geq 10$ cigarettes, $\mathrm{n}(\%)$ & $7(6.1)$ & $0(0.0)$ & $7(5.3)$ \\
\hline Mean (SD) & $3.3(3.0)$ & $1.8(1.6)^{*}$ & $3.1(2.9)$ \\
\hline Missing, $\mathrm{n}$ & 18 & 8 & 26 \\
\hline \multicolumn{4}{|l|}{ Typology of smokers** } \\
\hline Habit smoker, n (\%) & $43(24.3)$ & $3(4.6)^{* *}$ & $46(18.9)$ \\
\hline Chipper, n (\%) & $63(35.6)$ & $9(13.6)^{* *}$ & $72(29.6)$ \\
\hline Self-Stopper, n (\%) & $57(32.2)$ & $42(63.6)^{* *}$ & $99(40.7)$ \\
\hline Quitter, n (\%) & $14(7.9)$ & $12(18.2)^{*}$ & $26(10.7)$ \\
\hline Missing, $\mathrm{n}$ & 19 & 11 & 30 \\
\hline
\end{tabular}

Note: Age of smoking onset, days and number of cigarettes smoked in the past 30 days were categorized so that they can be compared with data from the Youth Risk Behavior Survey data by CDC. Gender differences: *: $\mathrm{p}<0.05$ and ${ }^{* *}: \mathrm{p}<0.01$. 
Among the 135 students who smoked in the past month, 33 (24.4\%) smoked daily, and 76 (57.1\%) smoked two or more cigarettes per day. With regard to smoking typology, $72(29.6 \%)$ were chippers, $46(18.9 \%)$ habit smokers, $99(40.7 \%)$ self-stoppers, and $26(10.7 \%)$ quitters. Significant gender differences were observed in smoking initiation $\left(71.3 \%\right.$ for boys and $27.4 \%$ for girls, $\left.\chi^{2}=106.77, p<0.001\right)$ as well as in other smoking measures (see Table 2). Significant gender differences were found in smoking typology: more boys were habit smokers $\left(24.3 \%\right.$ vs. $\left.4.6 \%, \chi^{2}=12.22, p=.0005\right)$ and chippers $\left(35.6 \%\right.$ vs. $\left.13.6 \%, \chi^{2}=11.12, p=.0009\right)$ and more girls were self-stoppers $\left(63.6 \%\right.$ vs. $\left.32.2 \%, \chi^{2}=19.67, p<.0001\right)$ and quitters $\left(18.2 \%\right.$ vs. $\left.7.9 \%, \chi^{2}=5.31, p=.02\right)$.

Smoking rates, with boys and girls combined and separately, assessed for all 7 measurement durations, are presented in Figure 1. When the measurement duration increased from one day to 30 days, the rate of smoking increased rapidly. After 30 days, increases were negligible. The pattern was consistent for boys and girls combined and respectively.

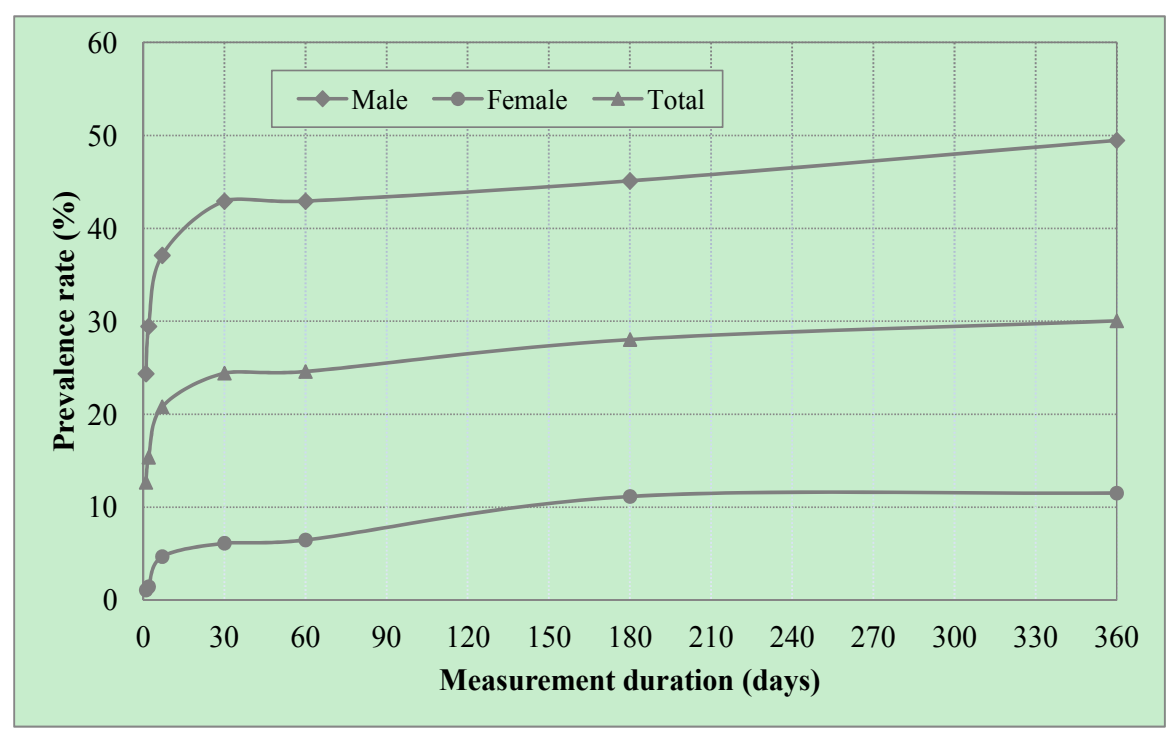

Figure1. Incidence (\%) of cigarette smoking measured for different durations, vocational high school students $(\mathrm{N}=553)$, Wuhan, China

Note: Measurement duration in days was derived using survey data with one week $=7$ days, one month $=30$ days, two months $=60$ days, 6 months $=180$ days, and one year $=360$ days.

\subsection{Association between Media Receptivity and Smoking}

The media receptivity score was 2.45 ( $\mathrm{SD}=0.83$ ) for boys and girls combined; boys scored (mean=2.55, $\mathrm{SD}=0.89$ ) significantly higher than girls (mean=2.36, $\mathrm{SD}=0.75$ ), $\mathrm{t}=4.52, \mathrm{p}<0.05$ from Student $\mathrm{t}$-test. The media receptivity scores ranged from 2.61 to 2.83 among students who smoked, and from 2.30 to 2.42 among non-smoking students. Results from Student $\mathrm{t}$-test show that media receptivity scores were significantly higher in smokers than in non-smokers across all eight smoking behavior measurements at various time durations ( $<<.05$ for all). In addition to media, perceived number of teachers and friends who were current smokers were also significantly associated with self-smoking as measured in all the measurements ( $\mathrm{p}<.05$ for all). More details are presented in Table 3. 
Table 3. Differences in media receptivity and perceived others smoking between smokers and non-smokers measured at varying smoking durations from one day to lifetime $(\mathrm{n}=553)$

\begin{tabular}{|c|c|c|c|c|c|c|c|c|}
\hline & \multicolumn{8}{|c|}{ Smoking duration } \\
\hline & Today & Past 2 days & Past week & Past 30 days & Past 2 months & Past 6 months & Past year & Lifetime \\
\hline \multicolumn{9}{|l|}{ Media receptivity score, } \\
\hline \multicolumn{9}{|l|}{ mean (SD) } \\
\hline Smoking students & $2.71(1.04)^{*}$ & $2.74(1.03)^{*}$ & $2.83(1.01)^{*}$ & $2.76(0.99)^{*}$ & $2.77(0.99)^{*}$ & $2.75(0.96)^{*}$ & $2.70(0.97)^{*}$ & $2.61(0.91)^{*}$ \\
\hline Nonsmoking students & $2.42(0.79)$ & $2.40(0.77)$ & $2.37(0.74)$ & $2.36(0.74)$ & $2.36(0.75)$ & $2.34(0.74)$ & $2.35(0.74)$ & $2.30(0.71)$ \\
\hline \multicolumn{9}{|l|}{ Father smoking, n (\%) } \\
\hline Smoking students & $54(77.14)$ & $64(71.11)$ & $85(73.91)$ & $101(74.81)$ & $100(73.53)$ & $115(74.19)$ & $125(74.40)$ & $187(69.00)$ \\
\hline Nonsmoking students & $313(69.09)$ & $301(70.00)$ & $287(69.32)$ & $271(69.13)$ & $273(68.94)$ & $260(68.60)$ & $257(68.17)$ & $198(70.71)$ \\
\hline \multicolumn{9}{|l|}{ Mother smoking, n (\%) } \\
\hline Smoking students & $3(4.35)$ & $4(4.49)$ & $3(2.63)$ & $5(3.73)$ & $6(4.44)$ & $5(3.25)$ & $6(3.61)$ & $10(3.72)$ \\
\hline Nonsmoking students & $16(3.56)$ & $15(3.51)$ & $17(4.14)$ & $15(3.86)$ & $14(3.56)$ & $15(3.99)$ & $14(3.73)$ & $9(3.24)$ \\
\hline \multicolumn{9}{|l|}{ Smoking teachers, } \\
\hline \multicolumn{9}{|l|}{ mean (SD) } \\
\hline Smoking students & $2.38(0.86)^{*}$ & $2.39(0.89)^{*}$ & $2.38(0.85)^{*}$ & $2.35(0.81)^{*}$ & $2.35(0.81)^{*}$ & $2.36(0.77)^{*}$ & $\begin{array}{c}2.34 \\
(0.78)^{*}\end{array}$ & $\begin{array}{c}2.23 \\
(0.77)^{*}\end{array}$ \\
\hline Nonsmoking students & $2.01(0.74)$ & $1.99(0.72)$ & $1.97(0.72)$ & $1.96(0.72)$ & $1.97(0.73)$ & $1.94(0.73)$ & $1.94(0.73)$ & $1.90(0.73)$ \\
\hline \multicolumn{9}{|l|}{ Smoking friends, } \\
\hline \multicolumn{9}{|l|}{ mean (SD) } \\
\hline Smoking students & $2.61(0.71)^{*}$ & $2.58(0.71)^{*}$ & $2.61(0.72)^{*}$ & $2.57(0.76)^{*}$ & $2.58(0.74)^{*}$ & $2.59(0.76)^{*}$ & $2.55(0.77)^{*}$ & $2.33(0.82)^{*}$ \\
\hline Nonsmoking students & $1.98(0.81)$ & $1.95(0.81)$ & $1.93(0.80)$ & $1.90(0.78)$ & $1.92(0.80)$ & $1.88(0.77)$ & $1.87(0.77)$ & $1.83(0.77)$ \\
\hline \multicolumn{9}{|l|}{ General public smoking, } \\
\hline \multicolumn{9}{|l|}{ mean (SD) } \\
\hline Smoking students & $3.05(0.45)$ & $3.04(0.48)$ & $3.08(0.45)$ & $3.05(0.41)$ & $3.05(0.40)$ & $3.06(0.43)$ & $3.08(0.47)$ & $3.06(0.48)$ \\
\hline Nonsmoking students & $3.08(0.53)$ & $3.08(0.53)$ & $3.08(0.53)$ & $3.09(0.54)$ & $3.09(0.55)$ & $3.08(0.54)$ & $3.07(0.53)$ & $3.08(0.56)$ \\
\hline
\end{tabular}

Note: Smoking teachers, smoking mothers, smoking friends, and smokers in general were assessed using students' perceptions (see text on measurement for details). *: $\mathrm{p}<0.05$ and $* *$ : $\mathrm{p}<0.01$ from Student t-test indicating significant differences between students who smoked and students who did not smoke.

Results of multiple logistic regression analyses of the four selected smoking behaviors are presented in Table 4, indicating that higher ATMRS scores were significantly associated with increased risk of smoking with odds ratio varying from the lowest of $1.62(95 \% \mathrm{CI}: 1.23,2.13)$ for past two-day smoking to the highest of $2.00(95 \%$ CI: $1.54,2.60)$ for past-week smoking. The associations remained significant after controlling for covariates such as age, gender, school performance and smoking of significant others. 
Table 4. Odds ratios and 95\% confidence intervals of factors associated with cigarette smoking assessed at various durations: results from logistic regression analysis

\begin{tabular}{|c|c|c|c|c|}
\hline Variable & Past 2 days & Past week & Past month & Past 6 months \\
\hline \multicolumn{5}{|c|}{ Model I (simple logistic) } \\
\hline Media receptivity & $1.62(1.23,2.13)$ & $2.00(1.54,2.60)$ & $1.81(1.41,2.32)$ & $1.82(1.44,2.31)$ \\
\hline \multicolumn{5}{|l|}{ Model fitting } \\
\hline $\begin{array}{l}\text { Likelihood ratio } \\
\text { ( } \mathrm{p} \text { value) }\end{array}$ & $12.05(<0.001)$ & $28.59(<0.001)$ & $23.46(<0.001)$ & $26.25(<0.001)$ \\
\hline$-2 \log L$ & 461.95 & 521.68 & 576.87 & 602.95 \\
\hline R-Square & 0.031 & 0.074 & 0.064 & 0.071 \\
\hline \multicolumn{5}{|c|}{ Model II (multiple logistic) } \\
\hline Father smoking & $1.05(0.57,1.94)$ & $1.27(0.70,2.28)$ & $1.25(0.71,2.22)$ & $1.38(0.81,2.34)$ \\
\hline Mother smoking & $0.90(0.20,4.17)$ & $0.29(0.06,1.38)$ & $0.58(0.14,2.38)$ & $0.40(0.10,1.55)$ \\
\hline Smoking teachers & $1.01(0.70,1.48)$ & $1.11(0.77,1.58)$ & $1.05(0.74,1.49)$ & $1.22(0.88,1.69)$ \\
\hline Smoking friends & $3.33(2.23,4.96)$ & $3.45(2.42,4.93)$ & $3.76(2.65,5.35)$ & $3.54(2.56,4.91)$ \\
\hline Media receptivity & $1.21(0.88,1.65)$ & $1.61(1.19,2.19)$ & $1.49(1.11,2.01)$ & $1.52(1.15,2.02)$ \\
\hline \multicolumn{5}{|l|}{ Model fitting } \\
\hline $\begin{array}{l}\text { Likelihood ratio } \\
\text { ( } \mathrm{p} \text { value) }\end{array}$ & $154.94(<0.001)$ & $180.37(<0.001)$ & $203.55(<0.001)$ & $192.16(<0.001)$ \\
\hline$-2 \log L$ & 375.31 & 411.33 & 469.57 & 491.70 \\
\hline R-Square & 0.262 & 0.330 & 0.301 & 0.309 \\
\hline
\end{tabular}

Note. One logistic regression was used for each of the four smoking measures in Model 1. In Model 2, the variables age, gender and school performance were included as covariates.

\section{Discussion}

\subsection{Prevalence of Cigarette Smoking}

In this study, we found that cigarette smoking is highly prevalent among Chinese vocational high school students, with $71.3 \%$ of the boys and $27.4 \%$ of the girls having tried smoking, and $45 \%$ of the boys and $6.3 \%$ of the girls having smoked in the past 30 days. The 30-day cigarette smoking rate, boys and girls combined was $25.6 \%$, almost identical to the $26.0 \%$ reported in a study with youth and adults sampled in six Chinese cities (Anderson et al., 2006), and much higher than the 8-10\% reported among Chinese regular high school students (Anderson et al., 2006; Xing, Ji, \& Zhang, 2006). Our findings provide new evidence that cigarette smoking among Chinese adolescents is at a higher level in 2012 than in 2006. This trend should raise alarm to the Chinese Ministry of Education and Health. Carefully planned strategies are needed to be in place to persuade students from initiating smoking, and help current smokers to quit.

\subsection{Typology of Cigarette Smoking}

Our data have documented, for the first time in a sample of Chinese adolescents, the various typologies of cigarette smoking such as habitual smokers, chippers, self-stoppers and quitters. The evidence regarding self-stoppers $(40.7 \%$, stopped smoking by themselves after a few trials) and chippers or social smokers $(29.6 \%$, smoked now and then without developing into a habit) is of particularly significance. Chipper smokers account for approximately $10 \%$ of adult smokers in the United States (Shiffman Kassel, Paty, Gnys, \& Zettler-Segal, 1994). The higher percentage of chippers among Chinese adolescents is, perhaps, consistent with a Chinese notion that smoking is a social lubricant ( $\mathrm{Li}$ et al 2012). Therefore, if the cultural perception is changed in a way that smoking is no longer perceived as a social lubricant, many Chinese youth may choose not to smoke. In 
addition, the high percentage of self-stoppers needs further research to understand factors and mechanisms influencing the behavior of self-stopping.

\subsection{Media Receptivity and Cigarette Smoking}

Despite the progressive legal measures of the Chinese government to ban tobacco-advertising since 1991, the students in our sample were highly receptive to pro-tobacco messages in the media. Furthermore, increased receptivity was associated with initiation and after-initiation smoking assessed at various durations, from days to weeks, months, up to one year. To our knowledge, this is the first study investigating receptivity to pro-tobacco media and its association with cigarette smoking among vocational high school students in China. Findings of this study clearly demonstrate the need for specific tobacco control measures in China, particularly behavioral intervention to reduce adolescents' receptivity and anti-tobacco social marketing to counter-attack tobacco advertising. The high levels of media receptivity reported in our study also support the conclusion by others that the legal measures of banning tobacco advertisement in China are ineffective (Li et al., 2009; Yang et al., 2010; Lau, Chen, \& Ren, 2012; Yang et al., 2012). In this case, an alternative approach for the Chinese Ministry of Health to control tobacco would be to strengthen anti-tobacco social marketing, an evidence-based and cost-effective strategy for tobacco control demonstrated in the West (Sutfin, Szykman, \& Moore, 2008; Scheier \& Grenard, 2010; Buller et al., 2011).

\subsection{Measurement Duration of Adolescent Smoking}

In this study, adolescents reported cigarette smoking at seven different measurement durations: today, in past two days, in the past week, in the past month, in the past two months, in the past six months, and in the past year. Coincidentally, our findings show that the conventional measurement of 30-day is an optimal choice to assess smoking behavior relative to other measurement periods, be it shorter or longer. One month is a relatively short period for event recall and the rates assessed during this period were substantially higher than rates measured by other duration measurements. It seems that increasing measurement durations results in limited increases in smoking. Furthermore, this pattern persisted for both boys and girls who have very different levels of cigarette smoking. It can be argued that our finding has added evidence that the 30-day measurement is indeed optimal.

Results from the association analysis between media receptivity and smoking indicate that the odds ratio was higher from smoking in the past week and past month than smoking assessed in today and in the past two days. Further increases in measurement duration resulted in no increases, even reduction in the same odds ratio. These findings suggest that for etiological research to assess factors associated with smoking, it is more efficient to measure smoking during the 7-30 day period. Epidemiologically, using more recent smoking behavior measure in a cross-sectional study also has the advantage of minimizing the reverse impact of smoking behavior on influential factors.

\subsection{Limitations}

Our study has at least two limitations. First, participants of this study were selected from one school. Although school size, enrollment criterion and the number of specialties were considered in school selection, and our findings are highly consistent with results reported from diverse samples across a number of geographic locations in China, caution should be used if the findings are extrapolated to settings elsewhere. Second, our results are based on a cross-sectional survey. Therefore, no causal conclusion can be warranted.

\subsection{Conclusion}

This study makes four contributions to the field. First, the findings have provided valuable information highly supportive of anti-tobacco campaigns as a strategy for tobacco control among adolescents in China. Second, the findings have added evidence justifying the selection of the past 30-day period of smoking as an optimal choice in behavioral epidemiological research. Third, the $25.6 \%$ smoking rate indicates that the prevalence of cigarette smoking among Chinese adolescents is unchanged or on the rise from 2006 to 2012, and should be of concern for educators, health care professionals and parents alike. Finally, the various typologies of cigarette smoking applied in our study (e.g., habitual smokers, chippers, self-stoppers and quitters) can be very useful to future researchers in the field. The findings with self-stoppers and social smokers are especially enlightening in the Chinese cultural context, where students pass cigarettes among themselves to be friendly, and/or social. There is a great chance that these cohorts may never become smokers if the media portray cigarette smoking in an unglamorous light, and if the cultural norm discourages using cigarettes as social lubricants.

\section{Acknowledgements}

This research was supported in part by the National Institute of Health (Awards \#: R01DA 022703, PI: Chen X.). We thank the participating students for their time and effort in completing the survey and the school 
administration and school teachers in assisting our work. Thanks also go to other research staff at Wuhan Centers for Disease Prevention and Control for their participation in conducting the survey.

\section{References}

Akers, R. L., \& Lee G. (1996). A longitudinal test of Social Learning Theory: Adolescent smoking. Journal of Drug Issues, 26(2), 317-343.

Anderson, J. C., Palmer, P. H., Chou, C. P., Pang, Z., Zhou, D., Dong, L., Xiang, H., Yang, P., Xu, H., Wang, J., Fu, X., Guo, Q., Sun, P., Ma, H., Gallaher, P. E., Xie, B., Lee, L., Fang, T., \& Unger, J. B. (2006). Tobacco use among youth and adults in Mainland China: The China Seven Cities Study. Public Health, 120(12), 1156-1169. http://dx.doi.org/ 10.1016/j.puhe.2006.07.023

Bandura, A. (1977). Social Learning Theory. New York, NY: General Learning Press.

Buller, D. B., Bettinghaus, E. P., Helme, D., Young, W. F., Borland, R., Maloy, J. A., Cutter, G. R., Andersen, P. A., \& Walther, J. B. (2011). Supporting tobacco control: Stimulating local newspaper coverage with a technical assistance website for local coalitions. Health Promot Pract, 12(6 Suppl 2), 186S-194S. http://dx.doi.org/10.1177/1524839911414563

Carson, N. J., Rodriguez, D., \& Audrain-McGovern, J. (2005). Investigation of mechanisms linking media exposure to smoking in high school students. Prev Med, 41(2), 511-520. http://dx.doi.org/10.1016/j.ypmed.2005.01.002

Chen, X., Cruz, T. B., Schuster, D. V., Unger, J. B., \& Johnson, C. A. (2002). Receptivity to protobacco media and its impact on cigarette smoking among ethnic minority youth in California. $J$ Health Commun, 7(2), 95-111. http://dx.doi.org/ 10.1080/10810730290087987

Chen, X., Li, Y., Unger, J. B., Gong, J., Johnson, C. A., \& Guo, Q. (2001). Hazard of smoking initiation by age among adolescents in Wuhan, China. Prev Med, 32(5), 437-445. http://dx.doi.org/10.1006/pmed.2001.0826

Chen, X., Li, X., Stanton, B., Mao, R., Sun, Z., Zhang, H., Qu, M., Wang, J., \& Thomas, R. (2004). Patterns of cigarette smoking among students from 19 colleges and universities in Jiangsu Province, China: a latent class analysis. Drug Alcohol Depend, 76(2), 153-163. http://dx.doi.org/10.1016/j.drugalcdep.2004.04.013

Chen, X., Stanton, B., Fang, X., Li, X., Lin, D., Zhang, J., Liu, H., \& Yang, H. (2006). Perceived smoking norms, socioenvironmental factors, personal attitudes and adolescent smoking in China: A mediation analysis with longitudinal data. $J$ Adolesc Health, 38(4), 359-368. http://dx.doi.org/10.1016/j.jadohealth.2005.03.010

China National Bureau of Statistics. (2011). 2010 Statistical Yearbook of China. Beijing, China: Statistics Press.

Coggins, C. R., Murrelle, E. L., Carchman, R. A., \& Heidbreder, C. (2009). Light and intermittent cigarette

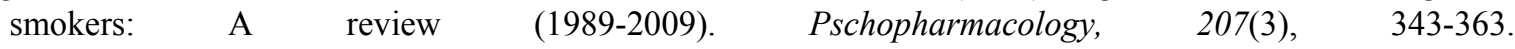
http://dx.doi.org/10.1007/s00213-009-1675-4

Feighery, E., Borzekowski, D. L., Schooler, C., \& Flora, J. (1998). Seeing, wanting, owning: The relationship between receptivity to tobacco marketing and smoking susceptibility in young people. Tobacco Control, 7(2), 123-128. http://dx.doi.org/10.1136/tc.7.2.123

Gilpin, E. A., Distefan, J. M., \& Pierce, J. P. (2004). Population receptivity to tobacco advertising/promotions and exposure to anti-tobacco media: Effect of Master Settlement Agreement in California: 1992-2002. Health Promot Pract, 5(3 Suppl), 91S-98S. http://dx.doi.org/10.1177/1524839904264601

Jatlow, P., Toll, B. A., Leary, V., Krishnan-Sarin, S., \& O'Malley, S. S. (2008). Comparison of expired carbon monoxide and plasma cotinine as markers of cigarette abstinence. Drug Alcohol Depend, 98(3), 203-209. http://dx.doi.org/10.1016/j.drugalcdep.2008.05.013

Jiang, Y., Yang, Y., \& Nan, Y. (2006). Global Youth Tobacco Survey (Gyts) in Four Cities of China, 2005. The 13th World Conference on Tobacco or Health: Building Capacity for a Tobacco-Free World. Washington, DC, United States.

Jones, S. E., Kann, L., \& Pechacek, T. F. (2011). Cigarettes smoked per day among high school students in the U.S., 1991-2009. Am. J. Prev. Med, 41(3), 297-299. http://dx.doi.org/10.1016/j.amepre.2011.05.018

Lau, M., Chen, X., \& Ren, Y. (2012). Increased risk of cigarette smoking among immigrant children and girls in Hong Kong: An emerging public health issue. J. Community Health, 37(1), 144-152. http://dx.doi.org/10.1007/s10900-011-9428-9 
Li, H. Z., Zhang, Y., MacDonell, K., Li, X. P., \& Chen, X. (2012). Counseling Chinese Patients about Cigarette Smoking: The Role of Nurses. Health Education: An International Journal, 112(4), 350-364.

Li, L., Yong, H. H., Borland, R., Fong , G. T., Thompson, M. E., Jiang, Y., ... Harris, F. (2009). Reported awareness of tobacco advertising and promotion in China compared to Thailand, Australia and the USA. Tob Control, 18(3), 222-227. http://dx.doi.org/10.1136/tc.2008.027037

Bohner, G., \& Dickel, N. (2011). Attitudes and attitude change. Annual Review of Psychology, 62, 391-417. http://dx.doi.org/10.1146/annurev.psych.121208.131609

Lindzey, G., \& Aronson, E. (1985). The Handbook of Social Psychology (Vol. 2, 3rd ed.). New York, NY: Random House.

Monroe, J. (2004). Getting a puff: A Social learning test of adolescents smoking. Journal of Child \& Adolescent Substance Abuse, 13(3), 71-83. http://dx.doi.org/10.1300/J029v13n03_04

Moore, M. (2012). The Global Dimensions of Public Health Preparedness and Implications for US Action. Am J Public Health, 102(6), e1-e7. http://dx.doi.org/10.2105/AJPH.2011.300644

Morissette, S. B., Gulliver, S. B., Kamholz, B. W., Duade, J., Farchione, T., Devine, E., ... Ciraulo, D. (2008). Differences between daily smokers, chippers, and nonsmokers with co-occurring anxiety and alcohol-use disorders. Addictive Behavior, 33(11), 1425-1431. http://dx.doi.org/10.1016/j.addbeh.2008.06.012

Naing, N. N., Ahmad, Z., Musa, Z. R., Hamid, F. R. A., Ghazali, H., \& Bakar, M. H. A. (2004). Factors related to smoking habits of male adolescents. Tob Induc Dis, 2(3), 133-140. http://dx.doi.org/10.1186/1617-9625-2-3-133

Pierce, J. P., Choi, W. S., Elizabeth, A., Gilpin, E. A., Farkas, A. J., \& Berry, C. C. (1998). Tobacco industry promotion of cigarettes and adolescent smoking. JAMA, 279(7), 511-515. http://dx.doi.org/10.1001/jama.279.7.511

Pierce, J. P., Garcia, M., Saltó, E., Schiaffino, A., \& Fernández, E. (2002). Tobacco advertising, does it increase smoking among teenagers? Data from California. Gac Sanit, 16(Suppl 2), 70-76.

Scheier, L. M., \& Grenard, J. L. (2010). Influence of a nationwide social marketing campaign on adolescent drug use. J Health Commun, 15(3), 240-271. http://dx.doi.org/ 10.1080/10810731003686580

Shiffman, S., Kassel, J. D., Paty, J., Gnys, M., \& Zettler-Segal, M. (1994). Smoking typology profiles of chippers and regular smokers. J. Subst. Abuse, 6(1), 21-35. http://dx.doi.org/10.1016/S0899-3289(94)90052-3

Sutfin, E. L., Szykman, L. R., \& Moore, M. C. (2008). Adolescents' responses to anti-tobacco advertising: Exploring the role of adolescents' smoking status and advertisement theme. J Health Commun, 13(5), 480-500. http://dx.doi.org/10.1080/10810730802198961

Tanski, S. E., Stoolmiller, M., Gerrard, M., \& Sargent, J. D. (2011). Moderation of the association between media exposure and youth smoking onset: Race/ethnicity, and parent smoking. Prev Sci, 13(1), 55-63. http://dx.doi.org/10.1007/s11121-011-0244-3

The Ministry of Education of China. (2011). The Education Statistics Yearbook of China. Beijing: The Chinese Ministry of Education Press.

The Ministry of Health of China. (2007). The First National Progress Report Regarding the Implementation of the WHO Tobacco Control Framework in the People's Republic of China. Beijing: The Ministry of Health of China press.

Unger, J. B., \& Chen, X. (1999). The role of social networks and media receptivity in predicting age of smoking initiation: A proportional hazards model of risk and protective factors. Addict Behav, 24(3), 371-381. http://dx.doi.org/10.1016/S0306-4603(98)00102-6

Wen, X., Chen, W., Muscat, J. E., Qian, Z., Lu, C., Zhang, C., .. Ling, W. (2007). Modifiable family and school environmental factors associated with smoking status among adolescents in Guangzhou, China. Prev Med, 45(2-3), 189-197. http://dx.doi.org/10.1016/j.ypmed.2007.02.009

World Health Organization. (2011). WHO Report on the Global Tobacco Epidemic, 2011: Warning about the Dangersof Tobacco. Geneva, World Health Organization. 
Xing, Y., Ji, C., \& Zhang, L. (2006). Relationship of binge drinking and other health-compromising behaviors among urban adolescents in China. J. Adolesc. Health, 39(4), 495-500. http://dx.doi.org/10.1016/j.jadohealth.2006.03.014

Yang, G., Fan, L., Tan, J., Qi, G., Zhang, Y., Samet, J. M., Taylor, C. E., Becker, K., \& Xu, J. (1999). Smoking in China: Findings of the 1996 National Prevalence Survey. JAMA, 282(13), 1247-1253. http://dx.doi.org/10.1001/jama.282.13.1247

Yang, G., Ma, J., Chen, A. P., Brown, S., Taylor, C. E., \& Samet, J. M. (2004). Smoking among adolescents in China: 1998 survey findings. Int J Epidemiol, 33(5), 1103-1110. http://dx.doi.org/ 10.1093/ije/dyh225

Yang, T., Rockett, I. R., Li, M., Xu, X., \& Gu, Y. (2012). Tobacco advertising, environmental smoking bans, and smoking in Chinese urban areas. Drug Alcohol Depend, 124(1-2), 121-127. http://dx.doi.org/10.1016/j.drugalcdep.2011.12.021

Yang, Y., Li, L., Yong, H. H., Borland, R., Wu, X., Li, Q., Wu, C., \& Foong, K. (2010). Regional differences in awareness of tobacco advertising and promotion in China: Findings from the ITC China Survey. Tob Control, 19(2), 117-124. http://dx.doi.org/ 10.1136/tc.2009.029868

Zheng, H., Sussman, S., Chen, X., Wang, Y. H., Xia, J., Gong, J., ... Johnson, C. A. (2004). Project EX-A teen smoking cessation initiation study in Wuhan, China. Addictive Behaviors, 29(9), 1725-1733.

\section{Copyrights}

Copyright for this article is retained by the author(s), with first publication rights granted to the journal.

This is an open-access article distributed under the terms and conditions of the Creative Commons Attribution license (http://creativecommons.org/licenses/by/3.0/). 